\title{
CAREERS
}

CONTEST Cash opportunities for energy entrepreneurs p.126
STUDENTSHIPS Train with bioscience leaders for industry careers $\mathbf{p . 1 2 6}$
NATUREJOBS For the latest career listings and advice www.naturejobs.com

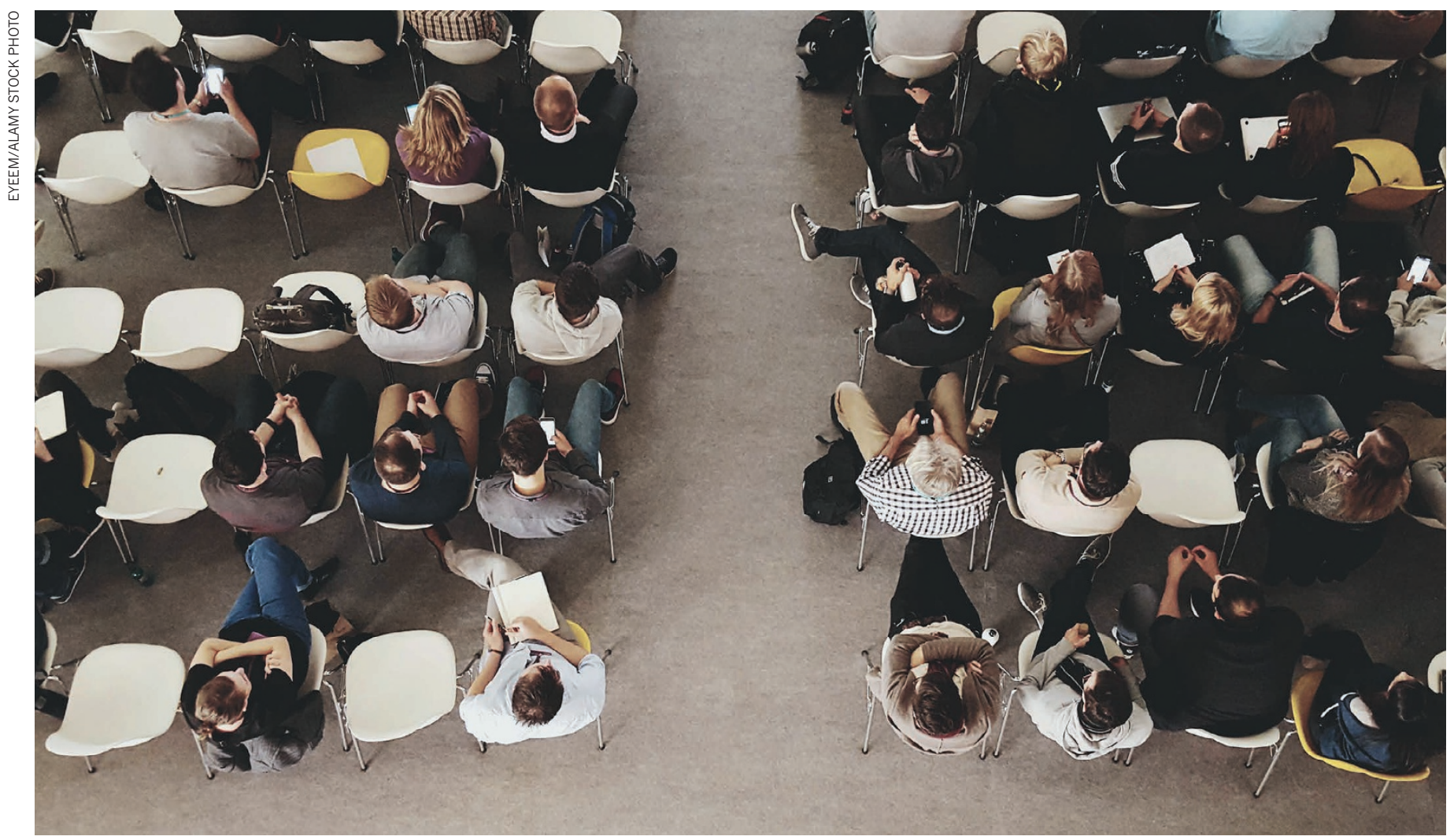

Getting together can help relieve PhD students' feelings of isolation.

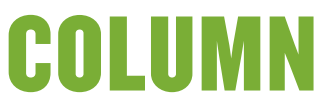

\section{By students, for students}

\section{Events at which PhD students share experiences can pay dividends.}

\section{BY THERESA MERCER}

$\mathrm{L}$ oneliness, writers' block and demotivation are just three of many challenges faced by PhD students across all disciplines. It was this realization that inspired me and a socialscience colleague to organize an event about the experience of being a $\mathrm{PhD}$ student.

So great was our fellow students' interest in our idea that what we'd originally conceived as a one-day workshop run by $\mathrm{PhD}$ students for $\mathrm{PhD}$ students turned into a two-day international conference. But it wasn't simple. Organizing and leading such an initiative as a student felt like a huge undertaking. And there were times when the organizing committee felt that it might not work. This was particularly the case at the beginning when we had only a seed of an idea and no experience among us in how to carry on with it.

But we learnt as we went. We planned sessions about the research and data-gathering experience; writing up and publishing results; getting through the viva or dissertation defence; and finding and defining the post-PhD path. And before long, members of the organizing committee and I were also adjusting bookings, applying for more money, fielding e-mails from attendees, keeping a budget, contacting key speakers and arranging catering. We presented our conference 'The PhD Experience' on 17-18 November 2008 at the University of Hull, UK.
We had 6 keynote and theme speakers from academia, government and industry, 6 student presenters, countless poster presentations and 160 attendees.

This kind of student-led training helped attendees, our organizers and me to realize that so many others at the same career stage face similar experiences and emotions. Although the whole endeavour was a great deal of work, at the same time I learnt so much - from the conference sessions themselves, and from my experience of co-organizing the whole thing.

And I wasn't the only one who benefited. Many of us forged new connections beyond our specific research disciplines and discovered a way forward beyond the 


\section{COMPETITION}

\section{Energy start-ups}

Energy entrepreneurs are invited to compete for a cash prize and the chance to network with investors. The German Energy Agency has launched Start Up Energy Transition, a global business competition open to start-ups and early-stage energy companies. Entrants can compete in five categories: Urban Energy Transition, for contributions to digitally enabled and sustainable cities; Cleantech Against Climate Change, for technologies that cut greenhousegas emissions; Future Production and Manufacturing, for digital solutions; Mobility Meets Energy Transition, for sustainable mobility concepts; and Platforms and Communities, for networks expansion. Entrants can also compete for a grand prize, Start Up SDG7, for companies or products that contribute to clean, affordable energy. Results will be announced in 2017. Category winners will each receive $€ 10,000$ (US $\$ 10,400$ ); the grand prize, a package worth $€ 20,000$, will be shared between three nominees. All entrants will have the chance to network with venture-capital representatives, industry partners and other start-ups. Applications may be submitted up to 31 January at go.nature.com/2hvk72h.

\section{TRAINING}

\section{Careers in bioscience}

The UK Biotechnology and Biological Sciences Research Council (BBSRC), a government-funded granting agency, has created collaborative $\mathrm{PhD}$ studentships that link doctoral students at participating universities with drugmakers and other industrial partners.

The £18.9-million (US\$23.9-million) investment in the Collaborative Training Partnerships programme will train $189 \mathrm{PhD}$ students for careers in bioscience. The ten lead industrial partners are AstraZeneca, Berry Gardens Growers, Croda International, Eli Lilly, GlaxoSmithKline, the Industrial Biotechnology Innovation Centre, MedImmune, Mondelez UK, Unilever UK and Waitrose.

Other companies and organizations are also taking part along with member universities; projects will be agreed between the industrial partners and collaborating institutions. The first round of studentships launches in October 2017 with additional rounds in October 2018 and 2019. Information for applicants will be available through the respective universities. $\checkmark$ doctorate. Attendees told us that the conference connected them with other students from different academic and cultural backgrounds and helped them to tackle the isolation that many of us feel by providing a non-judgemental environment in which to share the pleasures and pain associated with undertaking a $\mathrm{PhD}$.

All of us learnt about ways to juggle academic demands with those of our personal lives, how to address common pitfalls such as procrastination during writing and how to maximize the elation we experience when we reach key milestones.

So what have I learned? For my part, organizing and chairing $\mathrm{PhD}$ Experience taught me hard and soft skills and I gained more-informal insights. I feel better equipped to deal with the emotional and logistical aspects of an academic career as a physical scientist. I know how to put together and facilitate a conference or workshop - a task that many academic researchers will have to face. And because there's usually no formal training, it can be difficult to know where to start.

The experience has already proved fruitful in my current post, where I have organized a workshop for early-career academics on modelling ecosystem services. My team and I set up speakers, timetables, workshop logistics and advertising, and successfully bid for funding. The problemsolving skills I gained through organizing $\mathrm{PhD}$ Experience helped me to deal with unforeseen circumstances such as changing workshop dates - a complicated undertaking. And having gone through all of this before, I felt more prepared and less anxious about what needed to be done, and the process felt more efficient than if I had come to it cold.

$\mathrm{PhD}$ Experience also offered valuable insights into academic life. One was to do with writing papers and grant applications - I learnt that the tendency to put this off strikes researchers at every career stage. It is crucial, it seems, to find the best time to do focused work - identifying the 'golden hours' that must be blocked off in the diary and trying to get into a regular writing habit - if one is to sidestep the procrastination problem.

I also learnt that many of us confront another issue - making time to work through the emotions that peer review produces, and learning to view it as constructive criticism rather than personal attack. I have experienced the sting of flat-out rejection as well as receiving very positive comments on a manuscript. It is difficult to juggle all the different, and sometimes contradictory, opinions. But the conference taught me to adopt a steely determination, to deal with peer-review comments objectively - and carry on.

At PhD Experience we had invited researcher-speakers from various backgrounds. Some were mature students, with previous work experience. Talking to them or hearing their presentations about how they adjusted to re-entering academia has encouraged me to feel free to take a more meandering academic journey and to be involved in research projects that I truly enjoy.

Another lasting benefit from that early conference has been the strong bonds created from sharing experiences; I am still in contact with student speakers from the conference, many of whom now have academic careers. One close friend who presented at "Anotherlasting the conference now has an academic benefit from the conference has been the strong bonds created from sharing experiences." career abroad. We are cheerleaders for each other and provide a sympathetic ear when one of us faces problems. We also share networks, tips and relevant events with each other as we learn about living and working as an academic.

Although universities and research councils may provide research training for the $\mathrm{PhD}$, there is no substitute for learning and experiencing the process with your peers. The nature of the $\mathrm{PhD}$ is constantly changing and evolving. Students are now expected to come out of the process with more than just the technical knowledge of their field.

Not every PhD student could or would want to conceive, organize and produce a conference, but I believe there is much to gain by getting involved in student-led training, even if only as an attendee. You will learn softer skills - such as ways to deal with difficult situations and emotions in the workplace, and learning to relate to colleagues - that will prove invaluable in your career, whatever it may be.

For my part, I learned organizational and problem-solving skills, got insight into manuscript writing and the peer-review process and discovered how to build work-life balance and valuable networks. And I also came away with an appreciation for and a greater understanding of the power of working together and sharing common experiences and emotions.

Theresa Mercer is an environmental researcher at Cranfield University, UK.

\section{CORRECTION}

The Careers Feature 'Find your voice' (Nature 540, 157-159; 2016) misrepresented Steve Blank's role in the NSF Innovation Corps Program. He didn't just work with the programme, he is its architect. 